\title{
A Consecutive Cohort with COVID-19 in Wuhan, China: Natural History, Clinical Features and Considerations
}

\author{
Bin Sun, $M D^{1 \#}$, Hao Wang, $M D^{1 \#}$, Hui-Xia Xu1 and Gui-Jun Zhang, $M D^{2 *}$ \\ ${ }^{1}$ Department of Intensive Care Medicine, Qinghai Province People's Hospital, Xining, China \\ ${ }^{2}$ Department of Neurosurgery, West China Hospital, Sichuan University, GuoXue Xiang, Chengdu, Sichuan, China \\ ${ }^{\#}$ Bin Sun and Hao Wang contributed equally to this work
}

\begin{abstract}
Background: A novel type of coronavirus pneumonia was first reported in Wuhan in December 2019. Clinical features and prognosis of elder patients were still unclear, therefore, this study was on a purpose to provide a better understand of this disease.

Methods: The clinical chart of 28 patients was confirmedly diagnosed with COVID-19 were retrospectively reviewed, between 20 January 2020 and 24 February 2020.

Results: The clinical chart of 28 patients, including 18 males (64.3\%) and 10 males (ratio, 1.6:1), with the average age at the time of admission was $54.8 \pm 15.1$-years-old (Range, $23-81$ years-old). The most common symptoms and signs were cough $(n=24,85.7 \%)$. Older patients $(\geq 60)$ were more likely to be at a higher risk of death than their counterpart under $60(p=0.030)$. Compared with non-elderly group, the value and positive rates of HGB and ALB in elder group were more significantly increased $(p=0.035$ and $p=0.036 ; p=0.016$ and $p=0.019)$. Statistically significant difference was observed in value of PT and INR between these two groups $(p=0.031$ and $p=0.027)$.
\end{abstract}

Conclusions: The overwhelming part of older patients usually happened to dyspnea posterior to a short time of onset of initial symptom, which can quickly progress to critical condition.

Keywords

COVID-19, Prognostic factors, Treatment

\begin{abstract}
Abbreviations
APTT: Activated partial thromboplastin time; ALB: Albumin; ALT: Alanine aminotransferase; AST: Aspartate aminotransferase; BNP: Brain natriuretic peptide; BUN: Blood urea nitrogen; CK: Creatine kinase; CK-MB: Creatine kinase isoenzyme; CT: Computer tomographic; D-D: D-dimer; HGB: Hemoglobin; INR: International normalized ratio; L: Lymphocyte; LAC: Lacticacid; LDH: Lactate dehydrogenase; NHC: National Health Commission; PCT: Procalcitonin; PLT: Platelet; PT: Prothrombin time; RT-PCR: Real time-polymerase chain reaction; SD: Standard deviation; TBIL: Total bilirubin; WBC: White blood cells
\end{abstract}

\section{Introduction}

In December 2019, a novel type of coronavirus pneumonia was first reported in Wuhan, Hubei Province, China. The novel coronavirus infection, known as COVID-19, is caused by severe acute respiratory syndrome coronavirus 2 (SARSCov-2) $[1,2]$. In the early days, there was nothing we could do with this disease, and because of this, high rates of person-to-person transmission and mortality were still lasting. But, with the level-1 public health response initiated by Chinese government and stringent personal protective measures taken by Chinese people, China has successfully controlled the spread and improved the curative rate of COVID-19. Till in 07/05/2020 in China, confirmed 84407 cases of COVID-19 and 4643 deaths have been reported. Currently, an increasing number of studies have described the clinical characteristic, epidemiology, diagnosis, treatment and outcome about

*Corresponding author: Gui-Jun Zhang, MD, Department of Neurosurgery, West China Hospital, Sichuan University, No. 37 Guo Xue Xiang, Chengdu, 610041, Sichuan, China

Accepted: December 29, 2020

Published online: December 31, 2020

Citation: Sun B, Wang H, Hui-Xia X, et al. (2020) A Consecutive Cohort with COVID-19 in Wuhan, China: Natural History, Clinical Features and Considerations. J Clin Anesth Pain Manag 4(2):178-185 
Citation: Sun B, Wang H, Hui-Xia X, et al. (2020) A Consecutive Cohort with COVID-19 in Wuhan, China: Natural History, Clinical Features and Considerations. J Clin Anesth Pain Manag 4(2):178-185

COVID-19 infection. But clinical features and prognosis of elder patients was still unclear, with only limited literature reported. In addition, the long-term outcome of curable patients was not described in previous studies. Therefore, we mainly retrospective reviewed elder patients in severe condition from Wuhan city to provide information to give a better understanding of this disease.

\section{Materials and Methods}

The clinical chart of 28 patients was confirmedly diagnosed with COVID-19 from Wuhan Xinzhou distract people's hospital between 20 January 2020 and 24 February 2020 were retrospectively reviewed, including 18 males (64.3\%) and 10 males (ratio, 1.6:1) from Wuhan city of China with a mean age of $54.8 \pm 15.1$ years (Table 1 ). This study was approved by the ethics board of Wuhan Xinzhou distract people's hospital.

\section{Data collection}

Clinical data were retrospectively obtained from patients' medical, laboratory findings and chest computer tomographic (CT) scans. Clinical features included sex/age, symptoms as well as signs at admission and follow-up outcome. All patients with COVID-19 enrolled in this study were diagnosed by nucleic acid real time-polymerase chain reaction (RT-PCR) tests and treated based on the National Clinical guidelines (Edition 5) formulated by the China National Health Commission (NHC). Those with condition of one of the following clinical features was taken as a severe case: 1) Hypoxemia with reseing oxygen saturation $\leq 93 \%$; 2) Respiratory frequency $\geq$ 30 times/min; 3) arterial partial oxygen pressure $\left(\mathrm{PaO}_{2}\right) / \mathrm{ox}$ ygen absorption concentration $\left(\mathrm{FiO}_{2}\right) \leq 300 \mathrm{mmHg}(1 \mathrm{mmHg}$ $=0.133 \mathrm{KPa}$ ). In addition, the critically diagnostic criteria met one of the following conditions: 1) Respiratory failure and

Table 1: Clinical data of 28 severe/critical cases with COVID-19.

\begin{tabular}{|c|c|c|c|c|c|c|c|}
\hline No. & $\begin{array}{l}\text { Sex/age } \\
\text { (yrs) }\end{array}$ & Symptoms at admission & $\begin{array}{l}\text { Temperature } \\
\text { at admission }\end{array}$ & $\begin{array}{l}\text { Duration } \\
\text { (days) }\end{array}$ & $\begin{array}{l}\text { Length of } \\
\text { ICU (days) }\end{array}$ & $\begin{array}{l}\text { Status at } \\
\text { discharge }\end{array}$ & $\begin{array}{l}\text { Follow-up } \\
\text { (nucleic acid } \\
\text { tests) }\end{array}$ \\
\hline 1 & Male/81 & Anhelation and chest distress & 37.5 & 5 & 4 & Death & NA \\
\hline 2 & Male/36 & Dyspnea and cough & 39 & 12 & 8 & Death & NA \\
\hline 3 & Male/74 & $\begin{array}{l}\text { Anhelation, chest distress, cough and phlegm } \\
\text { cough and phlegm }\end{array}$ & 36.8 & 7 & 1 & Death & NA \\
\hline 4 & Female/71 & Cough & 36.8 & 3 & 5 & Death & NA \\
\hline 5 & Male/56 & Chest pain and cough & 40 & 21 & 9 & Death & NA \\
\hline 6 & Male/67 & Cough & 38 & 9 & 12 & Death & NA \\
\hline 7 & Male/68 & Chest distress, cough and phlegm & 37.5 & 10 & 7 & Death & NA \\
\hline 8 & Male/39 & Anhelation, chest distress, cough and phlegm & 36.8 & 6 & 4 & Death & NA \\
\hline 9 & Female/69 & Dyspnea, cough and phlegm & 39 & 4 & 9 & Death & NA \\
\hline 10 & Male/59 & Anhelation, chest distress and weakness & 38.6 & 10 & 38 & Death & NA \\
\hline 11 & Male/66 & Anhelation, chest distress, cough and weakness & 38.5 & 12 & 20 & Death & NA \\
\hline 12 & Male/33 & Cough and weakness & 38.8 & 8 & 17 & Survival & Negative \\
\hline 13 & Female/53 & Chest distress, cough and phlegm & 37.5 & 7 & 12 & Survival & Negative \\
\hline 14 & Male/67 & Anhelation, cough and phlegm & 36.5 & 5 & 30 & Survival & Negative \\
\hline 15 & Male/43 & Chest distress & 39 & 7 & 11 & Survival & Negative \\
\hline 16 & Male/30 & Chest distress and cough & 36.5 & 4 & 5 & Survival & Negative \\
\hline 17 & Female/52 & Chest distress, cough and weakness & 39.5 & 10 & 16 & Survival & Negative \\
\hline 18 & Male/50 & Cough and phlegm & 38.5 & 7 & 27 & Survival & Negative \\
\hline 19 & Female/39 & Anhelation, dyspnea, cough and pharyngalgia & 36.9 & 13 & 29 & Survival & Negative \\
\hline 20 & Female/58 & Cough and weakness & 39 & 4 & 10 & Survival & Negative \\
\hline 21 & Female/64 & Anhelation, cough and phlegm & 38.7 & 20 & 12 & Survival & Negative \\
\hline 22 & Male/48 & Anhelation, cough and phlegm & 38.7 & 23 & 30 & Survival & Negative \\
\hline 23 & Male/35 & Chest distress, cough and phlegm & 39 & 35 & 10 & Survival & Negative \\
\hline 24 & Female/69 & Chest distress, cough, phlegm and weakness & 38.1 & 8 & 20 & Survival & Negative \\
\hline 25 & Male/64 & Cough and weakness & 40 & 3 & 9 & Survival & Negative \\
\hline 26 & Male/23 & No & 38 & 2 & 3 & Survival & Negative \\
\hline 27 & Female/58 & Cough & 39 & 7 & 6 & Survival & Negative \\
\hline 28 & Female/62 & Chest distress and cough & 37.4 & 3 & 7 & Survival & Negative \\
\hline
\end{tabular}


Citation: Sun B, Wang H, Hui-Xia X, et al. (2020) A Consecutive Cohort with COVID-19 in Wuhan, China: Natural History, Clinical Features and Considerations. J Clin Anesth Pain Manag 4(2):178-185

mechanical ventilation is essential; 2) Shock; 3) Combined with other organ failure needing ICU care.

\section{Statistical analysis}

The use of mean or median was determined by the type and the normality of data; mean was used for continuous variables with normal distribution (distributed evenly or not) and median was used for data of abnormal distribution or rank variables, followed by Chi-square, independent sample t-test and Mann-Whitney u test for comparison. Furthermore, the spread of data (interquartile range [IQR] for median and standard deviation for mean) was provided. We chose the variables including patients' data and laboratory investigations in the present study, which was similar to published studies. The variables for statistical analysis included age, gender, symptoms as well as signs and WBC, HGB, LY, etc.

\section{Results}

In this study, between 20 January 2020 and 24 February
2020, we included 18 male patients (64.3\%) and 10 female patients $(35.7 \%)$, with a male female ratio of 1.8 . The average age at the time of admission was $54.8 \pm 15$.1-years-old (Range, 23-81 years-old). The mean and median times of duration of symptoms were $9.5 \pm 7.4$ and 7 days, respectively (Range, 2-35 days). The most common symptoms and signs were cough ( $n=24,85.7 \%)$, followed by fever $(n=22,78.6 \%)$, chest distress ( $n=13,46.4 \%)$, phlegm ( $n=12,42.9 \%)$, anhelation $(n=9,32.1 \%)$, weakness $(n=6,21.4 \%)$ and dyspnea $(n=$ $9,32.1 \%)$, weakness $(n=6,21.4 \%)$ and dyspnea $(n=3,10.7 \%)$; chest pain $(n=1,3.6 \%)$ and pharyngalgia $(n=1,3.6 \%)$ were not common. The median time from admission to ICU was 5 days (Range, 0-31 days). In regards to previous history, 16 patients $(57.1 \%)$ had hepatitis, 5 patients $(17.9 \%)$ had hypertension, 3 patients (10.7\%) had diabetes, 3 patients (10.7\%) had chronic obstructive pulmonary disease, 2 patients (7.1\%) had coronary heart disease. In addition, only 2 patients (7.1\%) had smoking history, all of which, in this study, did not significantly increase the risk of death (Table 1 and Table 2).

Table 2: Variables in death and survival patients with COVID-19.

\begin{tabular}{|c|c|c|c|c|c|}
\hline Variables & Normal range & $\begin{array}{l}\text { All } \\
28\end{array}$ & $\begin{array}{l}\text { Death } \\
11(42.9)\end{array}$ & $\begin{array}{l}\text { Survival } \\
17(57.1)\end{array}$ & $\mathbf{P}$ \\
\hline & & & Median \pm IQR & & \\
\hline Male & & $18(64.3)$ & $9(81.8)$ & 9 (52.9) & $0.124^{+}$ \\
\hline Duration of Symptoms, days & & & & & $0.794^{\ddagger}$ \\
\hline Range & & $2-35$ & $3-21$ & $2-35$ & \\
\hline Mean & & $9.5 \pm 7.4$ & $9.0 \pm 5.0$ & $9.8 \pm 8.7$ & \\
\hline Median & & 7 & 9 & 7 & \\
\hline Length of ICU, days & & & & & $0.258^{\ddagger}$ \\
\hline Range & & $1-38$ & $1-38$ & $3-30$ & \\
\hline Mean & & $13.3 \pm 9.7$ & $10.6 \pm 10.4$ & $14.9 \pm 9.1$ & \\
\hline Median & & 10 & 8 & 12 & \\
\hline WBC $\left(\times 10^{9} / L\right)$, Mean \pm SD & $04-10$ & $10.4 \pm 5.0$ & $12.0 \pm 3.6$ & $9.4 \pm 5.6$ & $0.186^{\ddagger}$ \\
\hline Increased & & $12(42.9)$ & $7(63.6)$ & $5(29.4)$ & $0.081^{+}$ \\
\hline L $\left(\times 10^{9} / L\right)$, Mean \pm SD & $0.8-4.0$ & $0.7 \pm 0.3$ & $0.7 \pm 0.4$ & $0.8 \pm 0.3$ & $0.776^{\ddagger}$ \\
\hline Decreased & & $19(67.9)$ & $8(72.7)$ & $11(64.7)$ & $0.493^{+}$ \\
\hline $\mathrm{HGB}(\mathrm{g} / \mathrm{L})$, Mean $\pm \mathrm{SD}$ & $110-160$ & $129.9 \pm 20.0$ & $137.3 \pm 19.6$ & $125.1 \pm 19.3$ & $0.117^{\ddagger}$ \\
\hline Decreased & & $6(21.4)$ & $2(18.1)$ & $4(23.5)$ & $0.561^{+}$ \\
\hline $\operatorname{PLT}\left(\times 10^{9} / \mathrm{L}\right)$, Mean \pm SD & $100-300$ & $221.1 \pm 111.9$ & $153.3 \pm 59.6$ & $265.1 \pm 117.1$ & $0.003^{\ddagger^{*}}$ \\
\hline Decreased & & $2(7.1)$ & $2(18.1)$ & $0(0)$ & $0.146^{\ddagger}$ \\
\hline РCT (ug/L) & $0-0.5$ & $0.2 \pm 0.2$ & $0.3 \pm 0.2$ & $0.2 \pm 0.1$ & $0.029^{1^{*}}$ \\
\hline Increased & & $3(10.7)$ & $2(18.1)$ & $1(5.9)$ & $0.336^{+}$ \\
\hline $\mathrm{BNP}(\mathrm{ng} / \mathrm{L})^{\S}$ & $0-300$ & $781.4 \pm 2018.4$ & $916.5 \pm 3000.3$ & $275.5 \pm 654.3$ & $0.157^{\natural}$ \\
\hline Increased & & $14(77.7)$ & $9(100)$ & $5(55.6)$ & $0.041^{+*}$ \\
\hline $\operatorname{ALT}(\mathrm{U} / \mathrm{L})$ & $0-40$ & $37.0 \pm 23.0$ & $37.0 \pm 27.0$ & $36.0 \pm 25.5$ & $0.495^{\natural}$ \\
\hline Increased & & $12(42.9)$ & $5(45.5)$ & 7 (41.2) & $0.565^{+}$ \\
\hline AST (U/L) & $0-40$ & $35.0 \pm 33.0$ & $41.0 \pm 37.0$ & $35.0 \pm 30.0$ & $0.706^{\natural}$ \\
\hline Increased & & $11(39.3)$ & $6(54.5)$ & $5(29.4)$ & $0.175^{+}$ \\
\hline ALB (g/L) & $30-50$ & $29.9 \pm 6.4$ & $26.9 \pm 2.9$ & $32.3 \pm 5.3$ & $0.002^{9^{*}}$ \\
\hline
\end{tabular}


Citation: Sun B, Wang H, Hui-Xia X, et al. (2020) A Consecutive Cohort with COVID-19 in Wuhan, China: Natural History, Clinical Features and Considerations. J Clin Anesth Pain Manag 4(2):178-185

\begin{tabular}{|c|c|c|c|c|c|}
\hline Decreased & & $16(57.1)$ & 10 (90.9) & $6(35.3)$ & $0.005^{+*}$ \\
\hline TBIL (umol/L) & $0-22$ & $17.4 \pm 12.5$ & $26.4 \pm 18.3$ & $13.2 \pm 9.0$ & $0.045^{1^{*}}$ \\
\hline Increased & & $9(32.1)$ & $6(54.5)$ & 3 (17.6) & $0.052^{+}$ \\
\hline BUN (mmol/L) & $2.5-9.4$ & $6.8 \pm 4.1$ & $7.2 \pm 7.2$ & $6.2 \pm 4.1$ & $0.115^{\natural}$ \\
\hline Increased & & $7(25)$ & 3 (41.7) & $4(23.5)$ & $0.581^{+}$ \\
\hline CK (U/L) & $24-204$ & $84.0 \pm 157.0$ & $118.0 \pm 402.0$ & $81.0 \pm 157.0$ & $0.588^{\natural}$ \\
\hline Increased & & $7(25)$ & $3(27.3)$ & $4(23.5)$ & $0.581^{+}$ \\
\hline CK-MB (U/L) & $0-24$ & $14.0 \pm 11.0$ & $17.0 \pm 18.0$ & $11.0 \pm 9.5$ & $0.028^{9^{*}}$ \\
\hline Increased & & 5 (17.9) & $4(36.4)$ & $1(5.9)$ & $0.062^{+}$ \\
\hline LDH (U/L) & $109-245$ & $409.0 \pm 233.0$ & $563.0 \pm 248.0$ & $380.0 \pm 136.5$ & $0.002^{9^{*}}$ \\
\hline Increased & & 26 (92.9) & $11(100)$ & $15(88.2)$ & $0.633^{+}$ \\
\hline $\mathrm{K}(\mathrm{mmol} / \mathrm{L})$ & $3.5-5.6$ & $3.9 \pm 1.1$ & $3.3 \pm 1.1$ & $4.1 \pm 0.8$ & $0.034^{9^{*}}$ \\
\hline Decreased & & $8(28.6)$ & $6(54.5)$ & $2(11.8)$ & $0.022^{+*}$ \\
\hline $\mathrm{Na}(\mathrm{mmol} / \mathrm{L})$ & $130-150$ & $137.0 \pm 5.0$ & $139.0 \pm 3.0$ & $135.0 \pm 4.0$ & $0.042^{9 *}$ \\
\hline Decreased & & $2(7.1)$ & 1 (9.1) & 1 (5.9) & $0.640^{+}$ \\
\hline PT (s) & Sep-14 & $12.4 \pm 2.7$ & $14.3 \pm 2.2$ & $11.8 \pm 2.0$ & $0.005^{1 *}$ \\
\hline Increased & & $7(25)$ & $6(54.5)$ & $1(5.9)$ & $0.007^{+*}$ \\
\hline APTT (s) & $22-38$ & $26.5 \pm 9.7$ & $31.6 \pm 11.0$ & $26.2 \pm 7.3$ & $0.063^{n}$ \\
\hline Increased & & $2(7.1)$ & $2(18.1)$ & $0(0)$ & $0.146^{+}$ \\
\hline INR & $0.8-1.5$ & $1.06 \pm 0.26$ & $1.2 \pm 0.2$ & $1.0 \pm 0.2$ & $0.006^{\pi^{*}}$ \\
\hline Increased & & $1(3.6)$ & $1(9.1)$ & $0(0)$ & $0.393^{+}$ \\
\hline D-D (ug/ml) & $0-1$ & $3.0 \pm 6.32$ & $4.3 \pm 12.4$ & $3.0 \pm 5.4$ & $0.689^{\natural}$ \\
\hline Increased & & 19 (67.9) & 7 (63.6) & $12(70.6)$ & $0.507^{+}$ \\
\hline LAC (mmol/L) & $0.5-2.0$ & $1.4 \pm 0.8$ & $1.5 \pm 1.4$ & $1.3 \pm 0.9$ & $0.187^{\natural}$ \\
\hline Increased & & $7(25)$ & $4(36.4)$ & 3 (17.6) & $0.249^{+}$ \\
\hline
\end{tabular}

(\%) is the percentage of the proportion in this group.

${ }^{*} \mathrm{P}<0.05 ;{ }^{\dagger}$ Chi-square test; ${ }^{\ddagger}$ Independent sample t-test; ${ }^{\circledR}$ Mann-Whitney $\mathrm{U}$ test; ${ }^{\S} 10$ cases were unavailable.

Eleven patients $(42.9 \%)$ died in ICU with uncorrectable hypoxemias; 17 patients (57.1\%) got a good recovery and then received self-quarantine for a range from 14 to 28 days. Complete follow-up data, at the most recent evaluation, were available for all survivors with a long-term follow-up duration of 3 months, and the nucleic acid tests (two times) were identified to be negative in those patients. But CT scans indicated that 6 patients still had mild inflammatory exudation.

Older patients were more likely to be at a higher risk of death than their counterpart ( $62.4 \pm 14.0$ vs. $49.4 \pm 3.4$ years, the median age; $p=0.030$ ). In terms of laboratory tests, the value and positive rate of ALB were more significantly decreased in death group than those in survival group $(p=0.002$ and $p=0.005$ ) and the value and positive rate of PT were more increased in death group than those in survivor group $(p=0.002$ and $p=0.007)$. There were statistically significant differences in level of PLT $(p=0.003)$, PCT $(p=0.029)$, TBIL $(p=0.045), C K-M B(p=0.028), L D H(p=0.002)$ and INR $(p=$ 0.006 ), but positive rates of these parameters did not reveal a significant difference between death and survivor group.

To be specific, patients with COVID-19 were divided into groups, as older group over 60-years-old and young group under 60 -years-old. There were 12 elder cases $(42.9 \%)$ among the 28 cases, with a mean age of $62.4 \pm 14.0$ years (Range $60-81$ years) and 7 cases (58.3\%) were males. The mean and median duration of symptoms in senior group were $7.4 \pm 5.0$ days and 6 days, respectively (Range, 3-20 days). The mean and median period of stay in ICU was $11.3 \pm 8.2$ days and 9 days (Range, 1-30 days), respectively after the date of the ICU admission. The most common symptoms of onset were cough $(n=11,91.7 \%)$, followed by fever $(n=9,75 \%)$ and chest distress $(n=6,50 \%)$. We made an attempt to obtain some different clinical behavior between elder and young adult group, and found that only more young adult patients $(n=11,84.6 \%)$ got a high fever $\left(38.5^{\circ} \mathrm{C}\right)$, which did not reach a statistical significance $(p=0.064)$ Table 3 .

With regards to laboratory test findings, compared with non-elderly group, the value and positive rates of HGB and ALB in elder group were more significantly increased $(p=$ 0.035 and $p=0.036 ; p=0.016$ and $p=0.019$ ). According to assessment of infection indicators, the value of PCT was more significantly increased in senior patients than those in young adult patients $(p=0.001)$, but positive rate of it did not any statistical difference between these two groups $(p=0.067)$. Statistically significant difference was observed in value of PT and INR between these two groups $(p=0.031$ and $p=0.027)$ Table 4. 
Citation: Sun B, Wang H, Hui-Xia X, et al. (2020) A Consecutive Cohort with COVID-19 in Wuhan, China: Natural History, Clinical Features and Considerations. J Clin Anesth Pain Manag 4(2):178-185

Table 3: Clinical Characteristics in elderly and non-elderly Patients.

\begin{tabular}{|c|c|c|c|c|}
\hline $\begin{array}{l}\text { Clinical characteristics } \\
\text { Overall n (\%) }\end{array}$ & $\begin{array}{l}\text { All } \\
28\end{array}$ & $\begin{array}{l}\text { Elderly } \\
12(42.9)\end{array}$ & $\begin{array}{l}\text { Non-elderly } \\
16(57.1)\end{array}$ & $\mathbf{P}$ \\
\hline Male & $18(64.3)$ & $7(58.3)$ & $11(68.8)$ & $0.430^{+}$ \\
\hline Duration of Symptoms, days & & & & $0.208^{\ddagger}$ \\
\hline Range & $2-35$ & $3-20$ & $2-35$ & \\
\hline Mean & $9.5 \pm 7.4$ & $7.4 \pm 5.0$ & $11.0 \pm 8.6$ & \\
\hline Median & 7 & 6 & 7.5 & \\
\hline Length of ICU, days & & & & $0.374^{\ddagger}$ \\
\hline Range & $1-38$ & $1-30$ & $4-38$ & \\
\hline Mean & $13.3 \pm 9.7$ & $11.3 \pm 8.2$ & $14.7 \pm 10.7$ & \\
\hline Median & 10 & 9 & 10.5 & \\
\hline \multicolumn{5}{|l|}{ Signs and symptoms } \\
\hline Fever, $\geq 38.5^{\circ} \mathrm{C}$ & $15(68.2)$ & $4(44.4)$ & $11(84.6)$ & $0.064^{+}$ \\
\hline Anhelation & 9 (32.1) & $5(41.7)$ & $4(25)$ & $0.299^{+}$ \\
\hline Dyspnea & $3(10.7)$ & $1(8.3)$ & $2(12.5)$ & $0.611^{+}$ \\
\hline Chest distress & $13(46.4)$ & $6(50)$ & $7(43.8)$ & $0.521^{+}$ \\
\hline Chest pain & $1(3.6)$ & $0(0)$ & $1(6.25)$ & $0.571^{+}$ \\
\hline Cough & $24(85.7)$ & $11(91.7)$ & $13(81.3)$ & $0.417^{+}$ \\
\hline Phlegm & $12(42.9)$ & $6(50)$ & $6(37.5)$ & $0.391^{+}$ \\
\hline Pharyngalgia & $1(3.6)$ & $0(0)$ & $1(6.25)$ & $0.571^{+}$ \\
\hline Weakness & $6(21.4)$ & $3(25)$ & $3(18.8)$ & $0.521^{+}$ \\
\hline Death & $11(39.3)$ & 7 (58.3) & $4(25)$ & $0.081^{+}$ \\
\hline
\end{tabular}

(\%) is the percentage of the proportion in this group.

${ }^{+}$Chi-square test; ${ }^{\ddagger}$ Independent sample t-test.

Table 4: Lab tests of COVID-19 in elderly and non-elderly patients.

\begin{tabular}{|c|c|c|c|c|c|}
\hline Variables & Normal range & $\begin{array}{l}\text { All } \\
28\end{array}$ & $\begin{array}{l}\text { Elderly } \\
12(42.9)\end{array}$ & $\begin{array}{l}\text { Non-elderly } \\
16 \text { (57.1) }\end{array}$ & $\mathbf{P}$ \\
\hline & & & Median \pm IQR & & \\
\hline WBC $\left(\times 10^{9} / \mathrm{L}\right)$, Mean \pm SD & $4-10$ & $10.4 \pm 5.0$ & $11.9 \pm 5.6$ & $9.3 \pm 4.4$ & $0.177^{+}$ \\
\hline Increased & & $12(42.9)$ & $7(58.3)$ & $5(31.3)$ & $0.148^{\ddagger}$ \\
\hline$L\left(\times 10^{9} / L\right)$, Mean $\pm S D$ & $0.8-4.0$ & $0.7 \pm 0.3$ & $0.7 \pm 0.3$ & $0.8 \pm 0.3$ & $0.446^{+*}$ \\
\hline Decreased & & $19(67.9)$ & $9(75)$ & $10(62.5)$ & $0.388^{\ddagger}$ \\
\hline $\mathrm{HGB}(\mathrm{g} / \mathrm{L})$, Mean $\pm \mathrm{SD}$ & $110-160$ & $129.9 \pm 20.0$ & $120.8 \pm 22.1$ & $136.7 \pm 15.7$ & $0.035^{+*}$ \\
\hline Decreased & & $6(21.4)$ & $5(41.7)$ & $1(6.25)$ & $0.036^{\ddagger *}$ \\
\hline $\operatorname{PLT}\left(\times 10^{9} / \mathrm{L}\right)$, Mean \pm SD & $100-300$ & $221.1 \pm 111.9$ & $181.4 \pm 101.0$ & $250.9 \pm 113.4$ & $0.105^{+}$ \\
\hline Decreased & & $2(7.1)$ & $2(16.7)$ & $0(0)$ & $0.175^{\ddagger}$ \\
\hline PCT (ug/L) & $0-0.5$ & $0.2 \pm 0.2$ & $0.3 \pm 0.1$ & $0.2 \pm 0.1$ & $0.001^{9 *}$ \\
\hline Increased & & $3(10.7)$ & $3(25)$ & $0(0)$ & $0.067^{\ddagger}$ \\
\hline $\mathrm{BNP}(\mathrm{ng} / \mathrm{L})^{\S}$ & $0-300$ & $781.4 \pm 2018.4$ & $916.5 \pm 3000.3$ & $275.5 \pm 654.3$ & $0.157^{\Uparrow}$ \\
\hline Increased & & $14(77.7)$ & $9(90)$ & $5(62.5)$ & $0.429^{\ddagger}$ \\
\hline $\operatorname{ALT}(U / L)$ & $0-40$ & $37.0 \pm 23.0$ & $44.0 \pm 49.0$ & $36.0 \pm 22.0$ & $0.430^{\prime \prime}$ \\
\hline Increased & & $12(42.9)$ & $6(50)$ & $6(37.5)$ & $0.391^{\ddagger}$ \\
\hline AST (U/L) & $0-40$ & $35.0 \pm 33.0$ & $35.0 \pm 36.0$ & $33.0 \pm 34.0$ & $0.834^{\pi}$ \\
\hline Increased & & $11(39.3)$ & $3(25)$ & $8(50)$ & $0.172^{\ddagger}$ \\
\hline
\end{tabular}


Citation: Sun B, Wang H, Hui-Xia X, et al. (2020) A Consecutive Cohort with COVID-19 in Wuhan, China: Natural History, Clinical Features and Considerations. J Clin Anesth Pain Manag 4(2):178-185

\begin{tabular}{|c|c|c|c|c|c|}
\hline ALB (g/L) & $30-50$ & $29.9 \pm 6.4$ & $27.5 \pm 2.5$ & $32.3 \pm 4.6$ & $0.010^{\text {ศ* }}$ \\
\hline Decreased & & $16(57.1)$ & $10(83.3)$ & $6(37.5)$ & $0.019^{\ddagger *}$ \\
\hline TBIL (umol/L) & $0-22$ & $17.4 \pm 12.5$ & $25.4 \pm 22.3$ & $13.2 \pm 7.6$ & $0.227^{\Uparrow}$ \\
\hline Increased & & $9(32.1)$ & $6(50)$ & $3(18.8)$ & $0.090^{\ddagger}$ \\
\hline BUN (mmol/L) & $2.5-9.4$ & $6.8 \pm 4.1$ & $9.2 \pm 10.0$ & $6.3 \pm 1.8$ & $0.210^{\uparrow}$ \\
\hline Increased & & $7(25)$ & $5(41.7)$ & $2(12.5)$ & $0.093^{\ddagger}$ \\
\hline CK(U/L) & $24-204$ & $84.0 \pm 157.0$ & $133.0 \pm 394.0$ & $81.0 \pm 140.0$ & $0.516^{\natural}$ \\
\hline Increased & & $7(25)$ & $4(33.3)$ & $3(18.8)$ & $0.328^{\ddagger}$ \\
\hline CK-MB (U/L) & $0-24$ & $14.0 \pm 11.0$ & $22.4 \pm 24.0$ & $13.0 \pm 5.0$ & $0.077^{\natural}$ \\
\hline Increased & & 5 (17.9) & $5(41.7)$ & $0(0)$ & $0.008^{\ddagger *}$ \\
\hline LDH (U/L) & $109-245$ & $409.0 \pm 233.0$ & $638.0 \pm 814.0$ & $385.0 \pm 121.0$ & $0.131^{9}$ \\
\hline Increased & & 26 (92.9) & 11 (91.7) & $15(93.8)$ & $0.683^{\ddagger}$ \\
\hline $\mathrm{K}(\mathrm{mmol} / \mathrm{L})$ & $3.5-5.6$ & $3.9 \pm 1.1$ & $3.3 \pm 1.4$ & $4.1 \pm 0.8$ & $0.103^{\natural}$ \\
\hline Decreased & & $8(28.6)$ & 7 (58.3) & $1(6.25)$ & $0.004^{\ddagger^{*}}$ \\
\hline $\mathrm{Na}(\mathrm{mmol} / \mathrm{L})$ & $130-150$ & $137.0 \pm 5.0$ & $139.0 \pm 7.0$ & $135.0 \pm 4.0$ & $0.013^{\text {१* }}$ \\
\hline Decreased & & $2(7.1)$ & $1(8.3)$ & $1(6.25)$ & $0.683^{\ddagger}$ \\
\hline PT (s) & $9-14$ & $12.4 \pm 2.7$ & $14.0 \pm 2.8$ & $11.6 \pm 1.7$ & $0.031^{9^{*}}$ \\
\hline Increased & & $7(25)$ & $5(41.7)$ & $2(12.5)$ & $0.093^{\ddagger}$ \\
\hline APTT (s) & $22-38$ & $26.5 \pm 9.7$ & $30.4 \pm 9.7$ & $24.8 \pm 8.0$ & $0.078^{\natural}$ \\
\hline Increased & & $2(7.1)$ & $2(16.7)$ & $0(0)$ & $0.175^{\ddagger}$ \\
\hline INR & $0.8-1.5$ & $1.06 \pm 0.26$ & $1.3 \pm 0.3$ & $1.0 \pm 0.2$ & $0.027^{\Re^{*}}$ \\
\hline Increased & & $1(3.6)$ & $1(8.3)$ & $0(0)$ & $0.429^{\ddagger}$ \\
\hline D-D (ug/ml) & $0-1$ & $3.0 \pm 6.32$ & $4.2 \pm 8.9$ & $2.8 \pm 0.3$ & $0.816^{\natural}$ \\
\hline Increased & & 19 (67.9) & $8(66.7)$ & $11(68.8)$ & $0.429^{\ddagger}$ \\
\hline LAC (mmol/L) & $0.5-2.0$ & $1.4 \pm 0.8$ & $2.2 \pm 1.5$ & $1.2 \pm 0.7$ & $0.094^{\pi}$ \\
\hline Increased & & $7(25)$ & $6(50)$ & $1(6.25)$ & $0.429^{\ddagger}$ \\
\hline
\end{tabular}

(\%) is the percentage of the proportion in this group;

${ }^{*} \mathrm{P}<0.05$; ${ }^{+}$Independent sample t-test; ${ }^{\ddagger}$ Chi-square test; ${ }^{\S}$ Mann-Whitney $\mathrm{U}$ test; ${ }^{\circledR} 10$ cases were unavailable.

\section{Discussion}

Since December 2019, the 2019 novel coronavirus, known as severe acute respiratory syndrome corona virus 2 (SARSCov-2), has been spreading quickly from its origin in Wuhan city of Hubei province of China to the rest of the country [1]. In this study, we clearly described the demographics and outcome of patients with COVID-19 to provide a better understanding and control of the COVID-19 epidemic.

The median age in our series at the time of diagnosis was 58-years-old, which was similar with previous studies that reported a median age at diagnosis of 59-years-old [1,3]. In consistent with those [4,5], our study indicated that larger age was an adverse predictor of poor outcome among patients with COVID-19 as escalating rates of severe/critical and mortality with increase in age. Unfortunately, no previous study, including this current one, has performed statistical analysis to identify the strong relation between outcome and age. It was obvious; however, old adults as high risk targets were susceptible to COVID-19 pandemic. The government should take powerful measures-outdoor activities limited, adequate isolation and earlier diagnosis-to control the potential com- munity spread of COVID-19. Since human-to-human transmission was a paramount factor of an epidemic that each patient spread infection to 2.2 other individual on average [3]. Additionally, some investigations have indicated that COVID-19 had a propensity to afflict males and male patients were more likely to experience a worse prognosis compare to females [6-9].

There were some significant differences, in this study, between young adult and older patients, in clinical behaviors and laboratory tests. The fever and cough were taken as the most common symptom in many previous studies and ours [9-12]. Our study revealed that compared with young adult patients ( $n=11,84.6 \%$ ), fewer older patients had a fever more than $38.5^{\circ} \mathrm{C}$, and this difference was treading toward a significance. Lian, et al. reported 15 that more older patients experienced shortness of breath and nasal obstruction. In regard to laboratory investigations, there were significantly decreased lever of ALB in older group than those in young adult group. A similar result was also reported by Lian, et al. [13] Moreover, the abnormal level of HGB, $\mathrm{K}^{+}, \mathrm{PT}$ and PCT (infection-related variable) were observed in the older group.

With regard to underlying disease, a small number of cas- 
Citation: Sun B, Wang H, Hui-Xia X, et al. (2020) A Consecutive Cohort with COVID-19 in Wuhan, China: Natural History, Clinical Features and Considerations. J Clin Anesth Pain Manag 4(2):178-185

es had it in which there was no significant difference between mild and severe/critical group [10]. Also, our study replicated its result. On the contrary to us, one study reported that significant difference was found in underlying condition between these two groups [13].

Many previous studies described that the value of LDH and PCT were significantly increased in the severe group than those in their counterparts $[6,10,12]$. This result was also confirmed in our study in which the increase in PCT or LDH was a risk predictor of death due to strong relation between $\mathrm{LDH} /$ PCT and cardiopulmonary as well as inflammation. In addition, elevated BNP and TBIL are more common in death patients, who had a significantly higher level than those in survivor patients. Plus, our cohort of dead cases also suggested that a poor prognosis observed a decrease in ALB. Moreover, the blood system and myocardium witnessed a devastating damage, the PT and CKMB were significantly in death group than those in survivor group $[7,14]$. We obtained a duplicated result.

Seventeen (57.1\%) severely ill ICU patients had died at median time of 8 days (Range, 1-38 days) mainly due to acute respiratory distress syndrome, shock, acute cardiac injury and coagulation dysfunction. But we failed to identify the severity as an independent risk factor of poor prognosis compared with young adult ICU patients, those more than 60-years-old were more subjective to these severe complications. Laboratory test, such as CK, BNP, D-dimer, should be given priority.

Sheng, et al. [15] reported that viral infection was related to a higher risk of pulmonary fibrosis which might cause one of the severe complications after patients recovered from COVID-19 infections. Among the 17 patients who were negative for two-time nucleic acid tests, 6 had CT findings of pulmonary inflammation malabsorption. It was requisite and imperative to address the issue that the prevention and treatment of pulmonary fibrosis in severe/critical patients recovered from COVID-19 infection.

\section{Conclusion}

Our study clearly reported and analyzed clinical behaviors and outcome in patients with COVID-19. Old patients are a vulnerable population, and the main symptoms are fever and cough. The overwhelming part of older patients usually happened to dyspnea posterior to a short time of onset of initial symptom, which can quickly progress to critical condition. Thus, potential risks of severe of complication should be closely taken notice of, and clinical behaviors as well as laboratory tests should be fully understood. Further randomized controlled clinical trials are required to give a comprehensive understanding of the variables in older adult with COVID-19 and to identify the independent factors of death.

\section{Credit Authorship Contribution Statement}

Bin Sun and Hao Wang: Conceptualization, Writing - review \& editing, Writing - original draft, Formal analysis, Methodology, Software.

Hui-Xia Xu: Resources.

Gui-Jun Zhang: Conceptualization, Writing - review \& ed- iting, Writing - original draft, Formal analysis, Methodology, Software and supervision.

\section{Declaration of Competing Interest}

We declare that we have no financial and personal relationships with other people or organizations that can inappropriately influence our work.

\section{Acknowledgments}

None.

\section{Quick Look}

\section{Current knowledge}

Clinical features and prognosis of elder patients was still unclear, with only limited literature reported. In addition, the long-term outcome of curable patients was not described in previous studies.

\section{What this paper contributes to our knowledge}

Our study clearly reported and analyzed clinical behaviors and outcome in patients with COVID-19. Older patients $(\geq 60)$ were more likely to be at a higher risk of death than their counterpart under 60 . Compared with non-elderly group, the value and positive rates of HGB and ALB in elder group were more significantly increased.

\section{References}

1. Wang D, Hu B, Hu C, et al. (2020) Clinical characteristics of 138 hospitalized patients with 2019 novel coronavirus-infected pneumonia in Wuhan, China. JAMA 323: 1061-1069.

2. Harapan H, Itoh N, Yufika A, et al. (2020) Coronavirus disease 2019 (COVID-19): A literature review. Journal of Infection and Public Health 13: 667-673.

3. Wang K, Zhao W, Li J, et al. (2020) The experience of high-flow nasal cannula in hospitalized patients with 2019 novel coronavirus-infected pneumonia in two hospitals of Chongqing, China. Ann Intensive Care 10: 37.

4. Wu Z, McGoogan JM (2020) Characteristics of and important lessons from the coronavirus disease 2019 (COVID-19) outbreak in China: Summary of a report of 72314 cases from the Chinese center for disease control and prevention. JAMA 323: 12391242.

5. CDC COVID-19 Response Team (2020) Preliminary estimates of the prevalence of selected underlying health conditions among patients with Coronavirus Disease 2019-United States, February 12-March 28, 2020. MMWR Morb Mortal Wkly Rep 69: 382-386.

6. Mills JP, Kaye KS, Mody L (2020) COVID-19 in older adults: Clinical, psychosocial, and public health considerations. JCI Insight 5: e139292.

7. Zheng Y, Xu H, Yang M, et al. (2020) Epidemiological characteristics and clinical features of 32 critical and 67 noncritical cases of COVID-19 in Chengdu. J Clin Virol 127: 104366.

8. Carley Eastin, Travis Eastin (2020) Clinical characteristics of coronavirus disease 2019 in China. J Emerg Med 4: 711-712.

9. Wang R, Pan M, Zhang X, et al. (2020) Epidemiological and clinical features of 125 hospitalized patients with COVID-19 in Fuyang, Anhui, China. Int J Infect Dis 95: 421-428. 
Citation: Sun B, Wang H, Hui-Xia X, et al. (2020) A Consecutive Cohort with COVID-19 in Wuhan, China: Natural History, Clinical Features and Considerations. J Clin Anesth Pain Manag 4(2):178-185

10. Ma J, Yin J, Qian Y, et al. (2020) Clinical characteristics and prognosis in cancer patients with COVID-19: A single center's retrospective study. J Infect 81: 318-356.

11. Guan WJ, Ni ZY, Hu Y, et al. (2020) Clinical characteristics of 2019 novel coronavirus infection in China. medRxiv.

12. Huang C, Wang Y, Li X, et al. (2020) Clinical features of patients infected with 2019 novel coronavirus in Wuhan, China. The Lancet 10223: 497-506.
13. Jiangshan L, Xi J, Shaorui H, et al. (2020) Analysis of epidemiological and clinical features in older patients with corona virus disease 2019 (COVID-19) out of Wuhan. Clin Infect Dis.

14. Rana QUA, Khan M, Haq A, et al. (2020) A review of coronavirus disease-2019 (COVID-19). Int J Biosci 16: 265-279.

15. Sheng $G$, Chen $P$, Wei $Y$, et al. (2020) Viral infection increases the risk of idiopathic pulmonary fibrosis: A meta-analysis. Chest 5: 1175-1187. 